\title{
O conceito de interferência nas relações literárias entre o Brasil e o Império português em África
}

\author{
Maria Teresa Salgado \\ Universidade de São Paulo
}

\begin{abstract}
RESUMO: ESTE TRABALHO PROCURA APONTAR A PROPRIEDADE DO CONCEITO DE INTERFERÊNCIA PARA O ESTUDO DAS RELAÇÕES LITERÁRIAS ENTRE O BRASIL E O IMPÉRIO PORTUGUÊS. O CONCEITO, SURGIDO A PARTIR DAS PROPOSTAS DA TEORIA DO POLISSISTEMA, DO TEÓRICO ITAMAR ZOHAR, PARECE ESPECIALMENTE INTERESSANTE PARA SE PENSAR AS RELAÇÕES LITERÁRIAS ENTRE BRASIL E ÁFRICA DESDE O PERÍODO COLONIAL. TAIS RELAÇÕES, FORAM INTENSAS E ENVOLVEM ASPECTOS QUE DIZEM RESPEITO NÃO SÓ À LITERATURA, MAS À CULTURA DE UM MODO GERAL.

RESUMEN: ESTE TRABAJO PROCURA APUNTAR LA PROPIEDAD DEL CONCEPTO DE INTERFERENCIA PARA EL ESTUDIO DE LAS RELACIONES LITERARIAS ENTRE BRASIL Y EL IMPERIO PORTUGUÉS. EL CONCEPTO, QUE SURGIÓ A PARTIR DE LAS PROPUESTAS DE LA TEORÍA DEL POLISISTEMA, DEL TEÓRICO ITAMAR ZOHAR, PARECE ESPECIALMENTE INTERESANTE PARA PENSAR LAS RELACIONES LITERARIAS ENTRE BRASIL Y ÁFRICA DESDE EL PERIODO COLONIAL. TALES RELACIONES, HAN SIDO INTENSAS Y HAN ENVOLVIDO ASPECTOS QUE DICEN RESPECTO NO SÓLO A LA LITERATURA, SINO TAMBIÉN ALA CULTURA DE UNA MANERA GENERAL.
\end{abstract}

PALAVRAS-CHAVE: CONCEITO DE INTERFERÊNCIA, RELAÇÕES lITERÁRIAS, BRASIL, ÁFRICA. PALABRAS-CLAVE: CONCEPTO DE INTERFERENCIA, RELACIONES LITERARIAS, BRASIL, ÁFRICA. 
uando preparava os pontos para o concurso que fiz, em julho de 2004, candidatando-me à vaga de Professor de Literaturas africanas na Universidade de São Paulo, um deles especialmente me despertou algumas dúvidas. O ponto chamava-se "Relações Literárias entre o Brasil e o Império Português na África”. Minha primeira indagação foi sobre a amplitude da palavra relações. Pensei, então, que um dado a ser levado em conta era o fato de que o discurso literário pode sugerir também aspectos mais amplos, uma vez que o sistema lingüístico manifesta-se como elaboração tanto de códigos literários (estilísticos, técnicos, etc) quanto paraliterários (temáticos, ideológicos, antropológicos. Assim sendo, o caráter vago do termo "relações" poderia dar conta de muitos aspectos. Tal idéia reforçava-se mais ainda, considerandose que as relações entre o Império Português na África e o Brasil foram de várias ordens - cultural, ideológica e política -, repercutindo-se naturalmente nas literaturas africanas então em formação. Concluí que a palavra "relações" pretendia dar conta das múltiplas esferas culturais ${ }^{1}$ e procurei verificar como a questão era vista por estudiosos da área. A partir dessa pesquisa, compreendi melhor a opção pela vagueza e amplitude do termo relações, como se poderá verificar pelo breve resumo das posições de alguns estudiosos na área de africanas que faço a seguir.

Embora saiba que outros importantes nomes se debruçaram sobre o assunto, mencionarei aqui apenas cinco pesquisadores pelos seguintes motivos: porque seus trabalhos, na época, me serviram como fonte para a elaboração para ponto da prova, porque suas pesquisas são referências representativas na área e também porque este artigo se pretende apenas como primeiras especulações. São eles o escritor e estudioso Mário Antonio, ${ }^{2}$ o Pro-

\footnotetext{
${ }^{1}$ A eleição de temas de caráter vago, para pontos de concurso, é, sem dúvida, positiva, uma vez que deixa ao candidato a liberdade para desenvolver o assunto como melhor the convier. Por outro lado, a vagueza do tema pode significar, também, que ainda há muito o que se discutir sobre determinados conceitos. ${ }^{2}$ OLIVEIRA, M. Antonio. "Influências da literatura brasileira sobre as literaturas portuguesas do Atlântico tropical”. Reler África. Coimbra: Centro de Estudos africanos, 1990.
} 
fessor Manuel Ferreira, ${ }^{3}$ o Professor Russell Hamilton, a Professora Maria Nazareth Fonseca ${ }^{4}$ e a Professora Maria Aparecida Santilli ${ }^{5}$.

Para discutir a questão, em 1968, Mário Antonio ${ }^{6}$ preferiu a expressão "influências literárias", que empregou já no título de seu artigo, sem necessidade de distingui-la de afinidades ou ressonâncias literárias, embora considerasse que o fenômeno não se circunscrevia à literatura. No ensaio desse estudioso, a palavra influência desfruta um significado amplo e antes corresponde a uma atitude de consciência das afinidades existentes, em vários aspectos, entre o Brasil e os países africanos de língua portuguesa. Mário Antonio cita uma série de fatores convergentes, que vão desde as rotas de comunicação que aproximavam os dois continentes até a semelhança de paisagens e de mitos, enfatizando as circunstâncias ecológicas como fundamentais para a ocorrência da influência literária. Em seu ensaio, o crítico destaca o caso dos escritores angolanos da geração de Mensagem e a própria influência que declara ter sofrido de escritores brasileiros como Manuel Bandeira ou Jorge Amado.

Maria Aparecida Santilli, em "Ecos do Modernismo Brasileiro entre africanos", artigo publicado em 1985, evita, desde o título de seu trabalho, adotar um conceito teórico mais comprometedor para abordar o tema. Santilli discute a repercussão da Literatura Brasileira, no espaço caboverdiano, destacando o papel do Modernismo no grupo de Claridade e especialmente a força da poesia de Bandeira em escritores desse grupo, como Osvaldo Alcântara e Jorge Barbosa. A expressão "intertextualidade programada" aparece uma única vez em seu artigo, quando se refere a Ovídio Martins, um poeta posterior ao grupo claridoso, que, no poema "Anti-evasão", escreve:

${ }^{3}$ FERREIRA, Manuel. "A emergência da intertextualidade afro-brasileira". O discurso no percurso africano I. Lisboa: Plátano, 1989.

${ }^{4}$ FONSECA, Maria Nazareth. "Presença da Literatura Brasileira na África de Língua Portuguesa". Contatos e Ressonâncias. LEÃO Angela V. (org.), Minas Gerais: Editora PUC Minas, 2003.

${ }^{5}$ SANTILLI, M. Aparecida. "Ecos do Modernismo Brasileiro entre Africanos". Africanidade, São Paulo: Ática, 1985.

${ }^{6}$ OLIVEIRA, M. Antonio. "Influências da literatura brasileira sobre as literaturas portuguesas do Atlântico tropical”. Reler Africa. Coimbra: Centro de Estudos africanos, 1990.

${ }^{7}$ SANTILLI, M. Aparecida. "Ecos do Modernismo Brasileiro entre Africanos". Africanidade, São Paulo: Ática, 1985. 
"Gritarei/ Berrarei/ Matarei// Não vou para Pasárgada". A pesquisadora menciona ainda a importância do Modernismo para a poesia angolana, reforçando a necessidade de uma pesquisa mais aprofundada sobre o assunto, quando afirma:

[...] o denunciado intercâmbio modernista da Literatura Brasileira com as africanas de Língua portuguesa está à espera dos que queiram juntar informações, levar o exame até a maior intimidade dos textos literários, documentos legítimos para atestar mais esta fecundação cultural entre os povos-parentes de lá e de cá. ${ }^{8}$

$\mathrm{Na}$ trilha de Santilli, Maria Nazareth Fonseca também prefere um termo mais amplo, como "presença", do que conceitos como "influência" ou "intertextualidade". Publicado em 2003, seu amplo e minucioso ensaio, "Presença da Literatura Brasileira na África de Língua Portuguesa", aborda não só a Literatura Angolana e Caboverdiana, mas também a Moçambicana no pré e pós-independência. Fonseca discute o papel dos textos literários brasileiros nas literaturas africanas e procura confrontar obras brasileiras e africanas, observando não só os pontos que as aproximam entre si, mas, sobretudo, os que distinguem e especificam a produção literária de autores africanos. Como afirma a pesquisadora: "mais que procurar identificar as semelhanças que comprovem a presença de Guimarães Rosa em textos de autores africanos contemporâneos, importa demonstrar essa presença exatamente pelas diferenças que a caracterizam". ' É o que faz Fonseca, em seu artigo, tanto para abordar produções textuais do período colonial quanto do pós-colonial.

Em ensaio intitulado "Influência e percepção do Brasil nas Literaturas Africanas de língua portuguesa", publicado também em 2003, Russell Hamilton enfatiza as importantes afinidades e conexões históricas entre o Brasil e a África, sublinhando a imagem prestigiosa que se fazia do Brasil entre os intelectuais e escritores da África lusófona:

${ }^{8}$ SANTILLI, M. Aparecida. "Ecos do Modernismo Brasileiro entre Africanos". Africanidade, São Paulo: Ática, 1985. p. 28.

${ }^{9}$ FONSECA, Maria Nazareth. "Presença da Literatura Brasileira na África de Língua Portuguesa". Contatos e Ressonâncias. LEÃO Angela V. (org.), Minas Gerais: Editora PUC Minas, 2003. p. 91. 
Tratava-se de uma sociedade crioula que surgiu no Atlântico Sul e que no século XIX emergiu do colonialismo para, no século XX, tornar-se ma potência mundial ou, pelo menos, uma potência entre as nações do chamado terceiro mundo. ${ }^{10}$

Citando o trabalho de Leonel Cosme, outro importante pesquisador da área, Hamilton chama a nossa atenção não apenas para os já conhecidos laços entre os escritores angolanos de Mensagem e os do nosso Modernismo, mas também para uma influência que se fez intensa até na crônica jornalística, com Davi Nasser, e na política, a partir do contato de brasileiros como Abdias do Nascimento. Este último, segundo o pesquisador americano, transmitiu aos jovens intelectuais angolanos os estatutos do Partido Comunista Brasileiro, inspirador de um modelo para o "primeiro movimento nacionalista multirracial apoiado nas massas populares - o MPLA" ${ }^{\text {"11 }}$ Hamilton rastreia e analisa, ainda, as influências da Literatura Brasileira em escritores como o angolano Mário Antonio e os caboverdianos Osvaldo Alcântara e Jorge Barbosa e conclui seu ensaio observando que a influência do Brasil nos cinco PALOP deve ser considerada tanto antes quanto depois da independência, sobretudo em função da constante presença de escritores africanos entre nós, seja vivendo, estudando ou trabalhando no país.

Por último, mas não por fim, o artigo "A emergência da intertextualidade afro-brasileira" parece ser um dos mais extensos estudos sobre o assunto. Nesse ensaio, Manuel Ferreira ${ }^{12}$ faz um longo inventário da presença da Literatura Brasileira em Angola, Moçambique e especialmente em Cabo-Verde, espaço onde, como declara o estudioso, "o fenômeno atingiu maior expressão e profundidade". Entretanto, a maior marca do artigo não é só a observação detalhada das relações que se estabeleceram entre Cabo Verde e Brasil em diversas esferas culturais, mas, em primeiro lugar, a opção pelo conceito de intertextualidade para discutir a questão. Daí, em seu comentário

\footnotetext{
${ }^{10}$ HAMILTON, Russell G. "A influência e percepção do Brasil nas literaturas africanas de língua portuguesa”. Contatos e ressonâncias. LEÃO, Ângela Vaz (org.)., Minas Gerais: Ed. PUC Minas, 2003. p. 142.

${ }^{11}$ Id. Ibid. p. 144.

${ }^{12}$ FERREIRA, Manuel. "A emergência da intertextualidade afro-brasileira". O discurso no percurso africano I. Lisboa: Plátano, 1989.
} 
final, o pesquisador procurar justificar a escolha do termo, trazendo o pensamento de Bakhtine, o teórico cujos trabalhos deram origem ao conceito de intertextualidade tal como foi desenvolvido por Julia Kristeva:

Com efeito, a intertextualidade é onipresente. Esta é outra verificação genial de Bakhtine, que veio depois a ser explorada por outros, com ênfase particular por Júlia Kristeva. Não há enunciado que não seja o produto da intercepção textual. É o caso que a via sinuosa e mui fecunda da influência, da interferência, da ruptura com a norma, ou seja, da intertextualidade, vai-se estendendo, aprofundando, lançando suas raízes que se reproduzem ad infinitum e vão dar novos frutos. ${ }^{13}$

Embora não retome diretamente a teoria da intertextualidade kristeviana, Ferreira recorre a teoria bakhtiniana do dialogismo para fundamentar o sucesso das fecundas relações culturais que se estabeleceram entre a África de Língua portuguesa e o Brasil.

A multiplicidade de enfoques para abordar o tema proposto não impede que estabeleçamos um consenso entre esses vários pontos de vista. E foi o que procurei fazer para desenvolver o ponto da prova, já que todos as abordagens e conceitos utilizados pelos pesquisadores evidenciavam antes aspectos complementares do que excludentes. As suas distintas opções pelos termos influência, ressonância, presença ou intertextualidade mostram-se igualmente válidas, considerando-se que revelam e exploram diferentes ângulos da questão. Entretanto, quase todos os artigos terminam por sugerir, como vimos pelos meus breves resumos, que há ainda um vasto campo a ser explorado em torno do assunto.

Há poucos meses, pude reforçar esse argumento e retomar as idéias sobre o tema em uma das discussões de um grupo de estudos de Literatura comparada da USP, organizado pelos professores Vima Lia, Hélder Garmes e Tânia Macedo e do qual também faz parte um significativo número de alunos dos cursos de Letras. A discussão do grupo enfocava o primeiro capítulo do livro Literatura

\footnotetext{
${ }^{13}$ FERREIRA, Manuel. "A emergência da intertextualidade afro-brasileira". O discurso no percurso
} africano I. Lisboa: Plátano, 1989. p. 185. 
comparada, publicado em 1997 pela pesquisadora Sandra Nitrini, ${ }^{14}$ professora também desta universidade. Em função do meu campo de estudos - Literaturas Africanas - interessei-me especialmente pela Teoria do polissistema de Even Zohar, ${ }^{15}$ cujos conceitos são muito bem expostos por Nitrini.

Não cabe aqui desenvolver uma exposição dessa teoria, até porque meu conhecimento sobre ela é ainda superficial. Contudo, desejo levantar alguns aspectos que demonstram a relevância da sua exploração para discutir as relações literárias entre África, Brasil e Portugal.

O primeiro aspecto liga-se ao fato de que a teoria do polissistema procura formular leis adequadas para a compreensão do fenômeno literário num determinado tempo e espaço, sobretudo como hipóteses temporárias e nunca como verdades eternas, marcando-se, assim, o seu caráter de permanente indagação em torno do fenômeno.Tal como a intertextualidade, a teoria do polissistema considera um contexto mais amplo do que o exclusivamente literário. No entanto, suas contribuições levam em conta ângulos não considerados pela proposta de Julia Kristeva.

Uma das grandes contribuições da teoria de Zohar é marcar a relação de interdependência entre os diversos fatores que "estão envolvidos com o conjunto de atividades para o qual o rótulo literário pode ser usado". ${ }^{16}$ Nesse sistema, não é, portanto, dada mais importância aos textos. Tampouco se privilegiam as obras canônicas em detrimento das não canônicas. Longe de perceber as periferias como categorias extra-sistêmicas, a teoria de Zohar reverte essa relação entre canônico e não canônico, evidenciando que "os textos, mais do que desempenharem um papel no processo de canonização, são o resultado desse processo". ${ }^{17}$ Os textos são, portanto, apenas manifestações parciais da literatura, integrando um sistema cultural que precisa ser visto em seus múltiplos aspectos, sem que se estabeleça entre eles uma escala hierárquica de importância.

Uma vez que as relações estabelecidas entre o Brasil e o Império Português se deram de modo intenso em várias áreas, como podemos constatar pe-

${ }^{14}$ NITRINI, Sandra. Literatura comparada. 2.ed., São Paulo: Edusp, 2000.

${ }^{15}$ ZOHAR, I. E. "Polysystems theory". Poetics Today, (1): 9-94, 1990. vol. 11

${ }^{16}$ NITRINI, Sandra. Literatura comparada. 2.ed., São Paulo: Edusp, 2000.

${ }^{17}$ Id. Ibid. p. 108. 
los citados artigos de pesquisadores da área, (não só a vida literária em seus múltiplos papéis e funções, mas também as outras artes, a religião, a política, a economia e demais campos da cultura) já se pode suspeitar a fecundidade que tal teoria oferece para o enfoque das literaturas africanas de língua portuguesa na perspectiva comparatista.

Mas é quando entramos em contato com o conceito de interferência, que Zohar nos oferece uma práxis comparatista bastante prolífica para discutirmos as literaturas produzidas a partir do colonialismo. Grosso modo, a definição de "interferência" parece à primeira vista nada acrescentar às propostas estabelecidas por termos como "influência", conceito profunda e sensivelmente explorado pelo poeta Valéry, ou "intertextualidade", termo que já é considerado praticamente um consenso, amplamente adotado nos estudos literários: "A interferência consiste numa relação entre literaturas por meio da qual uma certa literatura A (fonte literária) pode transformar-se em fonte de empréstimos direto ou indireto para uma outra literatura B (literatura alvo)". ${ }^{18}$ Esse conceito, entretanto, evidencia a questão da dependência, explicitando relações de poder e assim permitindo-nos refinar e entender, ainda mais detalhadamente, os vários trânsitos entre uma literatura fonte $\mathrm{e}$ uma literatura alvo.

As diferentes naturezas da interferência dependem, entre outros fatores, do grau de dependência estabelecido entre a literatura fonte e a literatura alvo. Está claro que "todas as literaturas passam por situações de interferência mais ou menos longa em algum momento de sua história." 19

No caso das literaturas africanas - caso dos sistemas dependentes - já sabemos, como mostra Zohar, que um sistema externo era indispensável para a sua formação. Mas a observação de sistemas literários ao longo da história da literatura permite a Zohar estabelecer formulações que podem ser transpostas para situações particulares sem anular as especificidades de cada caso. Comparem-se, por exemplo, os diferentes casos de literaturas minoritárias produzidas por grupos geograficamente conectados ou politicamente subjugados por um mais poderoso. Tome-se a situação da literatura americana em

\footnotetext{
${ }^{18}$ NITRINI, Sandra. Literatura comparada. 2.ed., São Paulo: Edusp, 2000. p. 110.

${ }^{19}$ Id. Ibid. p. 111.
} 
relação à inglesa, da flamenga em relação à alemã, e o caso que nos interessa, especificamente, das literaturas africanas de língua portuguesa em relação ao Brasil e a Portugal.

Vale marcar, sempre, que, ao procurar sistematizar várias leis de interferência, Zohar tem, em primeiro lugar, o intuito de demonstrar a possibilidade de formulá-las e investigá-las. ${ }^{20}$

Outro dado a ser considerado é o diálogo que podemos estabelecer entre as teorias de Zohar e as pesquisas de importantes teóricos da cultura, extremamente valiosas para os estudos das literaturas pós-coloniais. Ao declarar que a interferência nem sempre é óbvia, pois os canais de transferência podem estar na periferia, que não é visível do ponto de vista da cultura oficial, Zohar ${ }^{21}$ nos faz lembrar as idéias de Bhabha ${ }^{22}$ quando este declara, em $O$ local da cultura, que cada vez mais as culturas "nacionais" estão sendo produzidas a partir da perspectiva de minorias destituídas e que a moeda corrente do comparativismo crítico não é mais a soberania da cultura nacional concebida como propõe Benedict Anderson ${ }^{23}$. Do mesmo modo, ao indagar se as ideologias nacionais não procuram escamotear a interferência que de fato ocorre, Zohar ${ }^{24}$ termina por nos remeter também ao pensamento de Edward Said, quando este afirma que poucos estudos críticos, em grande escala, enfocaram a relação entre o imperialismo ocidental e a sua cultura, e o fechamento dessa relação profundamente simbiótica é um resultado da própria relação ${ }^{25}$. Tanto Said quanto Zohar sugerem, por exemplo, que é preciso examinar qual é o vínculo entre a busca de objetivos imperiais e a cultura nacional como um todo.

Este artigo não defende a adoção das teorias do polissistema de Zohar e de seu conceito de interferência em detrimento de nenhum dos conceitos ou terminologias normalmente empregados no campo dos estudos das literaturas africanas de língua portuguesa em suas relações com as Literaturas Brasileira e Portuguesa. Pretendeu-se, apenas, pôr em discussão um conceito que

\footnotetext{
${ }^{20}$ NITRINI, Sandra. Literatura comparada. 2.ed., São Paulo: Edusp, 2000.

${ }^{21}$ Id. Ibid. p. 112.

${ }^{22}$ BHABHA, Homi K. O local da cultura, Belo Horizonte: Ed. UFMG, 1998.

${ }^{23}$ Id. Ibid. p. 25.

${ }^{24}$ NITRINI, Sandra. Literatura comparada. 2. ed., São Paulo: Edusp, 2000. p. 114.

${ }^{25}$ SAID, Edward. Cultura e Imperialismo. São Paulo: Cia. das Letras, 1995, p. 39.
} 
se mostra bastante pertinente e que merece ser explorado, não apenas para abordar a produção literária em geral, mas para discutir as relações literárias nascidas a partir do colonialismo.

\section{Referências bibliográficas:}

BHABHA, Homi K. O local da cultura. Belo Horizonte: Ed. UFMG, 1998.

FERREIRA, Manuel. "A emergência da intertextualidade afro-brasileira". O discurso no percurso africano I. Lisboa: Plátano, 1989.

FONSECA, Maria Nazareth. "Presença da Literatura Brasileira na África de Língua Portuguesa”. Em Contatos e Ressonâncias. LEÃO, Angela V (org)., Minas Gerais: Editora PUC Minas, 2003.

HAMILTON, Russell G. "A influência e percepção do Brasil nas literaturas africanas de língua portuguesa". Contatos e ressonâncias, LEÃO, Ângela Vaz (org.)., Minas Gerais: Ed. PUC Minas, 2003.

NITRINI, Sandra. Literatura comparada. 2. ed., São Paulo: Edusp, 2000.

OLIVEIRA, M. Antonio Fernandes. "Influências da literatura brasileira sobre as literaturas portuguesas do Atlântico tropical". Reler Africa. Coimbra: Centro de Estudos africanos, 1990.

SAID, Edward W. Cultura e Imperialismo. São Paulo: Companhia das Letras, 1995.

SANTILLI, M. Aparecida. "Ecos do Modernismo Brasileiro entre Africanos". Africanidade, São Paulo: Ática, 1985.

ZOHAR, Evens, I.E. "Polysystems Theory”. Poetics today, vol. 11, (1): 9-94,1990. 